\title{
the search for the holy grant: (mis)allocating money in european political science
}

gerald schneider

Department of Politics and Management, University of Konstanz, Box D 86, D-78457

Konstanz, Germany

E-mail: gerald.schneider@uni-konstanz.de

\begin{abstract}
This article analyses the ways in which the research management apparatus set up by the European Commission and national-level research foundations contributes to the publication gap of European political science vis-à-vis the United States. I identify four structural problems in the allocation of money to individuals and institutions and derive two main recommendations from them. First, reviewers should be members of a merit-oriented European Academy of Political Science rather than stem from a group of arbitrarily chosen scholars. Second, the European Consortium for Political Research should seriously consider the introduction of individual membership and competitive leadership elections.
\end{abstract}

Keywords academic productivity; career incentives; European commission; research policy; ISI web of knowledge

Freedom is just another word for nothing left to lose,

Nothing, that's all that Bobby left me, yeah,

Kris Kristofferson and Janis Joplin, Me and Bobby McGee

\section{INTRODUCTION ${ }^{1}$}

$\mathrm{T}$ he late Mancur Olsen contended in his treatise on the rise and decline of nations that the demolition of 'distributional coalitions' renders a society more competitive (Olsen, 1982). Optimists might have assumed that the Europeanisation of research and education policy making would have the same effect. It could, in the best of all possible worlds, have led to a funding strategy that we often sadly miss at the national level - granting support to those projects and researchers who are truly innovative and internationally competitive. However, most of us would probably agree that the 'creative destruction', to use the Schumpeterian term, of tight scholarly cartels that have privileged access to national 
research grants has not yet taken place and is not likely to become a reality in the near future. What we have is, in contrast, quite often a prolongation if not a worsening of the anomalies that we encounter at the national level - rigid funding mechanisms in which powerful bureaucracies set the agenda and allocate scarce resources according to the catchphrases of the day rather than the excellence of the individual researcher.

The domination of bureaucratic interests over scientific innovation has not escaped sharp criticism. Two Italian expatriates working in the United States, the renowned economists Alberto Alesina and Roberto Perrotti (2004: 36), comment provocatively on the guidelines for the Sixth Framework Programme of the European Union (EU): the directives 'denote a vision of "research policy" grossly at odds with the model we believe is prevalent in most Anglo-Saxon countries: this includes a notion of scientific innovation as, almost by definition, unpredictable; and a role of public funding of research as encouraging innovation rather than imposing straightjackets on what is admissible research'.

This article will analyse why the Europeanisation of research policy has been without beneficial consequences until now and how the situation could be improved. To this end I will largely, but not exclusively, focus on the European Commission and make four main points: (1) the funding of European political science through national and European channels is inadequate, leading to superficial research and unoriginal teaching; (2) the available funds are often misallocated to unwieldy research projects that deliver legitimisation rather than critical insights; (3) the dirigisme in which some (but not all) Commission officials engage deters some of the brightest minds from looking for support from Brussels in the first place; (4) as researchers often find themselves in the role of the petitioner '...the dirigisme in which some (but not all) Commission officials engage deters some of the brightest minds from looking for support from Brussels in the first place...'

rather than the independent scientist, they only find support for applied rather than much needed cross-border basic research.

\section{THE FOUR PROBLEMS}

\section{INADEQUATE FUNDING}

The expansion of higher education in Europe has gone hand in hand with the Europeanisation of research and teaching. However, the budgets for public education and research have not grown at the same rate as the number of enrolled students. According to Eurostat, research and development expenditure as a proportion of GDP largely stagnated within the 'old' European Union between 1994 and 2004, increasing slightly from 1.89 to 1.94 per cent. The proportion grew in the United States, which saw a much more impressive expansion of its economy than Western Europe, from 2.4 to 2.59 per cent, while in the economically stagnating Japan an increase from 2.58 to 3.15 per cent could be observed.

At the same time, the student-teacher ratio in universities has remained largely unchanged during the past ten years: 22.13 in 1993 , it was 21.22 in 2003 . The same inertia can be observed in the relationship between research and development expenditure, and the number of enrolled students. The figure was approximately $€ 12,000$ per student in 1999 and $€ 13,000$ in 2003 . $^{2}$ The true figures 
are about one-fourth of these sums as only a quarter of all research and development expenditure actually goes to the university sector. According to the OECD, the corresponding average figures are much higher in the United States where around $\$ 18,000$ per student was spent in 2002.

Furthermore, such short-term comparisons neglect long-term developments, figures for which, unfortunately, only exist for individual countries. In a pioneering study, Thomas Plümper and Christina Schneider (2007) examined how unemployment affected student enrolment and state funding for students in the German Länder from 1975 to 2000. As in other European states, in Germany this period witnessed the development of what is called the 'Massenuniversität' ('Mass university') and, as a consequence, an increasing move away from the Humboldtian ideal of 'teaching based on research'. Plümper and Schneider (2007) reject the optimistic view that universities have just become more efficient during the past few decades. They rather present ample evidence that politicians use access to universities as a substitute for paying unemployment benefits. Students are, in other words, cheaper and, as they enjoy higher social status, also easier to silence than unemployed people in the post1968 era. According to the calculations of Plümper and Schneider (2007), unemployment is a strong predictor of university enrolment and helps particularly to explain why the social sciences and other relatively 'cheap' disciplines in the humanities have expanded to the detriment of the more expensive natural sciences, engineering and medicine. It would be interesting to see whether the expansion of higher education has followed a similar logic in other European states.

What are the effects on research and development of inadequate levels of funding? Although there are no quasiexperimental studies on the consequences that changing inputs have for research productivity, it is reasonable to assume that not so much the quantity but rather the quality of the published research suffers. The situation of a department that faces a worsening financial situation is similar to that of an orchestra unable to find sufficient time to rehearse because the musicians are forced to teach students or to drive taxis in order to earn a living. If such a financially stretched orchestra is unable to cut down the number of performances it is required to give, then it will with increasing frequency play pieces that are undemanding and do not require extensive practice. ${ }^{3}$ In an academic context, a lack of funds means that researchers do not have sufficient time to think through challenging ideas properly. They will rather publish light-weight papers that summarise the achievements of other people.

Another possible escape route that a researcher can take in times of financial stress is the recycling of ideas that he or she has developed previously. Underfunding will thus not necessarily lead to fewer publications, but to a shortfall in the number of high-impact papers and books. This under-performance on the research front cannot easily be dismissed using the argument that political scientists do not anyhow contribute important insights to public debates. By contrast, the lack of research competitiveness also affects the skills of generations of students and thus of future public officials and politicians. Instructors who do not actively contribute to scientific debates are only able to present second-hand thinking to their students. Hence, instead of relying on their own expertise, professors will increasingly draw on ideas and concepts that have been developed elsewhere, most likely on the other side of the Atlantic. 


\section{UNINTERESTING AND UNWIELDY PROJECTS}

Although an expansion of public (or private) funding for political science research and teaching is desirable, larger budgets are no panacea. The precondition for a more successful European political science is, rather, that the money be spent wisely. In Germany and elsewhere, funding still largely follows the so-called 'Giesskannenprinzip' that can be translated as the 'watering can principle'. This derogatory expression stands for the tendency of funding agencies to distribute subsidies indiscriminately among institutions, professors and students like a gardener who continues to water spots where no plant has ever grown. ${ }^{4}$ If one considers the size of some of the subsidised research networks, the funding decisions of the European Commission often seem to follow a similar logic.

We can draw on the lessons of neoinstitutionalism to see whether the current institutional setting prevents the misallocation of funds or rather furthers it. In my view, the main institutional hindrance to innovation and excellence in research is the overly large influence that the European Commission exerts in funding decisions. In most member states, relatively independent agencies, in which scientists rather than research officers have the biggest say, are responsible for the allocation of resources. Moreover, there are, at least in the larger states, often several competing agencies so that researchers are not forced to please a powerful bureaucracy or a handful of reviewers when writing researchgrant applications.

In the EU, by contrast, the European Commission is itself responsible for determining research themes, for selecting referees and for choosing projects; the European Science Foundation is still a relatively weak institution whose funding activities, by and large, are limited to the support of scientific meetings. The monopoly that the Commission enjoys at the European level is especially problematic for colleagues from member states in which national research foundations are under-funded or where the social sciences are discriminated against in comparison to the natural sciences.

The limited accountability of the European Commission aggravates the problems that the monopoly necessarily brings about. Obviously, the Commission has to reckon with the European Parliament and the Council of Ministers in its attempts to set the research agenda. However, its discretionary power is overly large because its fate is in the hands of twenty-seven masters (or twenty-eight, if we also consider the European Parliament) rather than one. Divergences among these principals over budgetary priorities, as we saw in 2005 over the decision on the British rebate, increase the discretionary power ('bureaucratic drift') of the agent, as the scholarship on principal agent-models has shown (Weingast and Moran, 1983; Franchino, 2007).

The power of the Commission affects the selection of topics that are ultimately deemed worthwhile and that make it onto the list of thematic priorities within the framework programmes. Admittedly, the Commission initiated 'open' calls for thematic proposals for the Sixth Framework Programme. Thereupon it was so overwhelmed with ideas that the selection of the final list of topics seemed arbitrary at best and self-serving at worst. The proliferation of EU-funded programmes that use the belittling term 'governance', instead of less loaded terms like 'government' or 'politics', indicates how successful the bureaucracy is in motivating scholars to do research that will certainly not threaten the Commission too much. As one roundtable participant observed during the ECPR meeting in Budapest, this politicised selection of 
research topics also leads to an underrepresentation of questions that do not deal with the EU itself.

Obviously, rigorous performance evaluations of individual research projects and grant applicants could alleviate the problem that the formulation of narrow and politicised research priorities furthers the publication of articles and monographs with limited scientific impact. However, although the EU uses a complex reporting system that is certainly more developed than those of several nationallevel institutions, the Commission does not stress academic excellence sufficiently. As some colleagues have remarked, financial honesty seems to matter more in the reports sent to Brussels than the intellectual achievements of research teams. This imbalance is a consequence of the pressures to which the European Commission has been subject since the scandals of the 1990s which, on one occasion, led to the resignation of the entire body. The only danger that this monopolist faces as a funding agency are reports of blatant waste and mismanagement. As the Luxembourgbased European Court of Auditors only wakes up if it hears the cry 'Fraud!' the production of irrelevant results does not matter much.

Hence, the European Commission will, like most monopolists, try to avoid taking risks. In e-mail correspondence with the author, one frustrated colleague reported that the rejection of a large-scale research project was explicitly based on the fear that the excellently qualified, multinational team would pursue a project with uncertain outcomes. In other words, the project was too risky in the view of the Commission and its reviewers.

Such a risk-averse attitude to basic research is in clear contrast to the selfunderstanding of most scientists. The eminent computer scientist John Holland (2005) has argued that even a 10 per cent success rate for the truly innovative

\section{'As the Luxembourg based European Court of Auditors only wakes up if it hears the cry 'Fraud!' the production of irrelevant results does not matter much.'}

projects would be sufficient. Obviously, government officials will never be as open to risk-taking as this. However, forcing the research community to focus on such lofty topics as 'features of a knowledge based society in line with European social models and the need to improve the quality of life' (quoted in Alesina and Perrotti, 2004: 36) through the carrot of possible research grants, will mainly attract two sorts of scholars - those who are driven by extrinsic rather than intrinsic motivations, and those who are in need of money to keep the lab running or who wish to explore various European destinations.

\section{DIRIGISME AND LACK OF INTEREST IN BASIC RESEARCH}

If one talks with colleagues about their experience of writing research-grant proposals for the EU's framework programmes, one frequently hears terms such as 'nightmare'. As the EU is a political body with very heterogeneous interests and a, still considerable, degree of mistrust between member states, the need to regulate all eventualities is somehow understandable. Yet, the cost of the Byzantine application procedure and excessive reporting is that some of the greatest minds are deterred from writing proposals in the first place.

A further impediment to scientific innovation is that the demands of the research bureaucracy take important time away from research. In an EU 
network with several Nobel Prize candidates, the team was asked to engage much more heavily in 'interdisciplinary' work with other teams of lesser known people. Admittedly, receiving a research grant creates some obligations. However, to force top academics to think about remote fields or marginal theories and methods and to force them to 'connect' with other people with whom they have nothing in common besides the professorial title distracts their attention and ultimately lowers the quality of the scientific output.

The reviewers that the European Commission hires cannot necessarily tame this dirigisme. Although many leading colleagues have evaluated research projects up to now, the possibility of applying for an evaluator position makes reviewers very dependent on the Commission. This self-selection also fails to ensure that the most experienced and outstanding colleagues are recruited for the crucial job of evaluating European research projects. It should be noted that other recruitment mechanisms are not necessarily better. In corporatist Germany, all formally qualified members of a professional association elect their so-called 'Fachgutachter' for the German Research Foundation. This mechanism certainly guarantees that nationally popular and renowned colleagues act as reviewers, but it remains doubtful whether the truly innovative, who will necessarily hurt scientific tradition, stand a chance at the ballot box.

One feature that the framework programmes share with many grant schemes at the national level is that the funding agency expects politically 'usable' results from the applicants. The money that is spent on applied research is, however, then subtracted from the budget for basic research. The redistribution and accompanying state intervention into the research priorities of academics are selfdefeating as 'basic research is crucial for the strategic position of industrialized nations in the world economy, and for remaining at the leading edge of technology' (Salter and Martin, 2001: 528). It often seems as if policy makers have not learned this lesson. A particularly blatant example of neglect is that the European Commission at one point considered scrapping the Eurobarometer and thus a tool that is useful for both academics and policy makers. Even though one could discuss the merits of this survey in detail and easily find ways to improve the questionnaires as well as the sampling of respondents, we need more data sets like this. Fortunately, the Seventh Framework Programme will emphasise data collection. We have thus some hope that European political science will be able to engage in large-scale and long-term data collection efforts like, for instance, the ones under the auspices of the Correlates of War project that have benefited our American colleagues so much. Whether the other announced changes - especially the devotion to the funding of basic research - has the desired effect of substituting the European 'medianocracy' with a true meritocracy remains to be seen.

\section{WHAT IS TO BE DONE?}

I have argued that many of the problems European political science faces have to do with the way in which scarce resources for teaching and research are allocated across institutions and researchers. Although I have paid more or less exclusive attention to the activities of the EU, similar points could be made about the funding agencies that operate at the national level. I believe, however, that the malaise at the European level is graver than in many member states of the EU and that the decision-making mechanisms at this level therefore need especially careful attention.

To make European political science more competitive, we need to reform 
the formal and informal rules that govern allocation decisions. Although my advice may seem contradictory at first sight, I firmly believe that we need both more and less democracy.

\section{LESS DEMOCRACY}

Funding institutions often pursue a 'divide et impera' strategy, granting some support to each and every scholar over the long term so that more or less everyone who writes a research-grant proposal is successful at some point. Such non-discrimination will, however, continue to frustrate the innovative scholars and diminish their motivation to excel in their work. At the same time, the misguided equal treatment creates an opportunity for the less productive scholars to free ride to the detriment of their more prolific colleagues.

The obvious solution to this serious research impediment is that funding agencies pay more attention to merit in evaluating scholarly work and grant proposals, and stop paying attention to secondary considerations like the geographical representativeness of a proposed research team. For this to happen, we need either the strengthening of the European Science Foundation at the expense of both national-level science foundations and the European Commission (which seems to be under way), or the creation of a truly independent (and wellendowed) European Research Foundation. Within this institution, we would need to create advisory panels to which the most successful and innovative senior political scientists would be co-opted. Although I might risk crucifixion for this, my recommendation would be that colleagues who have contributed more than a dozen visible articles or books in a broad range of high-impact outlets should be treated as candidates for this steering circle of excellence. Obviously, the glory alone is not enough; such referees should

\section{'...we need fewer thematic straitjackets tailored by public officials and more independent research projects by individual scholars or small groups of particularly eminent colleagues.'}

also receive modest remuneration for their service to the discipline. Furthermore, we need fewer thematic straitjackets tailored by public officials and more independent research projects by individual scholars or small groups of particularly eminent colleagues.

\section{MORE DEMOCRACY}

Although independent agencies are to be preferred to politicised actors in many domains ranging from monetary to competition policy, we cannot count on them exclusively in deciding about research and teaching. European political science needs strong representation in which both junior and senior scholars have a voice. In my view, the best solution would be to move from organisational to individual membership of the ECPR. Within this renovated organisation, individual members should be able to elect the leadership themselves; other professional organisations within our discipline like the American Political Science Association or the International Studies Association introduced competitive elections some years ago and their experience seems positive. $^{5}$

Individual membership would, in my view, also render the various and already excellent ECPR journals more visible. Admittedly, the most recent ISI Web of Knowledge ranking of political science 
journals puts the European Journal of Political Research (EJPR) and thus the flagship journal of the organisation among the very top journals in political science. However, previous rankings did not include the EJPR among the leading twenty-five journals of the discipline. Proper incentives could make the international standing of European journals more permanent. If members had to pay for this and other journals themselves, they would create pressure to ensure that only the very best articles were published in these and other European outlets. It should be noted that European journals have already gained some ground in recent years, thereby helping to transform political science into a more global enterprise. Three other European-based publications, European Union Politics, the Journal of Peace Research and the Journal of Theoretical Politics were also placed among the leading ten political science journals in 2006, while only JPR and the
Journal of Common Market Studies made it onto this list in 2005.

One of the tasks of the directly elected ECPR leadership would be to talk to the funding agencies on a regular basis. We need to convince the European Commission or its future functional equivalent that basic research in the social sciences is necessary and that we need some common resources like large-scale data sets in order to enable us to compete and to collaborate with our colleagues worldwide.

The bottom line of my argument is therefore that one important precondition for an increased competitiveness of European political science is thorough structural reform. To paraphrase Janis Joplin, European political science will only become free if there is something to loose sufficient resources, excellent publication outlets and funding agencies in which excellence in teaching and research is the decisive criterion and which still represent the entire field.

\section{Notes}

1 Although this short essay might give the impression that I am behaving like the Aesopian fox in relation to the sour grapes, I would like to stress that I am currently participating in the Sixth Framework Programme and have contributed frequently to ECPR activities, including three co-authored articles in EJPR and one in this journal. My intention is simply to highlight some structural problems in the allocation of resources for research and teaching. I have received comments on this article from Thomas Plümper, Nina Wiesehomeier and some additional colleagues who prefer their names to be withheld; none of these scholars should be held in any way responsible for the views expressed in this article.

2 Own calculations based on the figures available on the Eurostat homepage.

3 For a related argument in the context of regime compliance, see Downs et al (1996).

4 At the time of writing, the 'Exzellenzinitiative', through which German universities have started to apply for large research grants, is still under way. Although it is too early to assess this attempt to change the incentives for higher education, it seems very questionable to let whole universities with hundreds of professors compete against each other for the desired membership of the 'excellent' rather than the 'mediocre' category instead of individual departments.

5 At the moment, local representatives of the member organisations elect the ECPR leadership. Such an electoral system works well enough in situations in which these delegates are true representatives of their departments' members. However, it does mean that small departments have disproportionate influence. A direct ballot among individual members thus seems preferable.

\section{References}

Alesina, A. and Perrotti, R. (2004) 'The European Union: a politically incorrect view', Journal of Economic Perspectives 18: 27-48.

Downs, G.W., Rocke, D.M. and Barsoom, P.M. (1996) 'Is the good news about compliance good news about cooperation?' International Organization 50(3): 379-406. 
Franchino, F. (2007) The Powers of the Union: Delegation in the EU, Cambridge: Cambridge University Press.

Holland, J. (2005) 'Communication to the workshop on 'The Shadow of the Future', University of Michigan, 23-25 September.

Olsen, M. (1982) The Rise and Decline of Nations, New Haven: Yale University Press.

Plümper, T. and Schneider, C.J. (2007) 'Too much to die, too little to live: unemployment, higher education policies and university budgets in Germany, 1975-2000', Journal of European Public Policy, (forthcoming).

Salter, A.J. and Martin, B.R. (2001) 'The economic benefits of publicly funded basic research: a critical review', Research Policy 30: 509-532.

Weingast, B.R. and Moran, M.J. (1983) 'Bureaucratic discretion or congressional control? Regulatory policymaking by the Federal Trade Commission', Journal of Political Economy 91(5): 765-800.

\section{About the Author}

Gerald Schneider is Professor of Political Science at the University of Konstanz, Germany, where he has held the International Relations Chair since 1997. He is also Executive Editor of European Union Politics. His main research interests are in the areas of political decisionmaking, regional integration and political conflict. 